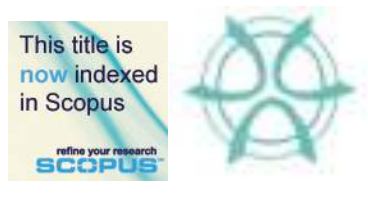

PLANNING MALAYSIA:

Journal of the Malaysian Institute of Planners

SPECIAL ISSUE IV (2016), Page 243 - 250

\title{
HUMAN BEHAVIOUR IN OPEN SPACE AROUND SPRING WATER IN A CENTRAL AREA OF MITO-CITY IN JAPAN
}

\author{
Takayuki Kumazawa ${ }^{1}$ \\ ${ }^{1}$ College of Engineering \\ IBARAKI UNIVERSITY, HITACHI, JAPAN
}

\begin{abstract}
In this study, this study demonstrated a transition of surround environment and human behavior around each spring water. Firstly, 38 places of spring water remaining in Mitocity were investigated. As results, spring water was used as drinking water, washing water and fire water. Spring water close to farmland was used as water for agriculture. However, in recent years, although water quality was degraded, it could no longer be used as drinking water. Therefore, a park with hydrophilic water is recently building. Some water located around shrines was sacred place as a God of water and place for cleanse themselves. In addition, some spring water was used as a method of environmental education, prevention training and ponds for fish. From these findings, this study proposes multipurpose spring water use in future.
\end{abstract}

Keyword: Human behavior, hydrophilic water, spring water, Water front, Open space

\section{INTRODUCTION}

Spring water has been used in people's daily life water from the old days. In the spring space, culture of the region has been nurtured while having a close relationship with life. In addition, spring water plays a very large role, in order to maintain and conservation of animal and plant habitat. But amount of spring water has been reduced by the influence of recent urbanization. Relationship of life and spring water diminished by the spread of water supply facilities. As results, awareness of the presence of spring water has disappeared. Spring water is valuable as a cultural resources of the region and important as water of securing and firefighting water at the time of the disaster. In these circumstance, guidelines for spring water conservation and revival by the Ministry of the Environment in Japan in March 2010 has been issued. In recent years, there has been a growing movement toward conservation and revival of spring water. When previous papers were reviewed, there was few papers discussed spring water and human behavior.

In this study, the spring water areas that are currently also remaining in Mito city centers were investigated. Transformation process of exploitation, 
Takayuki Kumazawa

Human Behaviour in Open Space Around Spring Water in a Central Area of Mito-City in Japan

topography and utilization of spring water has been investigated. In addition, how to remake spring water in future was proposed.

\section{OBJECTIVE AND METHODS}

Firstly, spring water remained on 38 places in Mito city centers was found. Distribution of all 38 locations of spring areas, current present condition, type of topography, installation, and positional relationship between neighbor temples and shrines were investigated. Field survey of spring water was carried out in 2 to 30 December 2014. This study was assumed to be flowed out to the surface of the spring water in the natural state.

Next, some spring water, where installation was seen in setting scene among 38 spring water, were investigated. In these areas, hearing was practiced. Items about hearing research were constructed from current utilizations of spring water, changes in the spring of the surrounding environment up to the present, current development conditions and factors for these transformation. Participants in hearing were residents and people engaged in neighbor temples and shrines. Survey date was a total of 10 days of December 2014.

\section{RESULTS INVESTIGATION INTO LOCATIONS, CONDITIONS< TOPOGRAPHIES AND CIRCUMSTANCES OF SPRINGS}

Figure 1 shows spring water locations in a central area of the Japanese city of Mito. There are 5 areas in which spring water is concentrated. After comparing locations and topography, spring water appears to be more distributed along cliff lines, such as mountain slopes, cliff bottoms, and valleys. Table 1, shows the condition, topography, and circumstance of the spring water. Figure 2 shows types of topography. Type a) is a cliff-line type gushing from the cliff face of a plateau-terrace; type b) is a valley-head type gushing from valley terrain, such as a horseshoe, type c) is wetland or pond type groundwater seeping into the lowland. The examination results of all 38 locations show that $75 \%$ of the spring locations are of a cliff-line type, a), and that $25 \%$ are a valley-head type, b). Many springs are fragmentarily spread along the cliff line, and from a small valley distant from the cliff. The next survey checked whether or not there are installations at the springs. In this study, an installation is considered to be a space directing human behavior into a certain setting according to space planning. The results confirmed installations at 34\% of the springs. Furthermore, these installations are currently accessible. There is a difference in height of installations. We also confirmed that $26 \%$ of springs neighbor temples and shrines. If springs are located close to temples and shrines, they are presumed to have some relationship.

Thus, springs are concentrated in five areas. Additionally, there is a tendency at some locations for spring water to flow into the ground. Table 1 shows different tendencies in present condition, types of topography, and 
installations. Specially, it was predicted that there would be a close relationship between installations and neighboring shrines, and that daily use at shrines would contribute to the active use of spring water. Based on this analysis, it was predicted that 18 springs are connected to installations or shrines. The next sections analyze these 18 locations in detail.

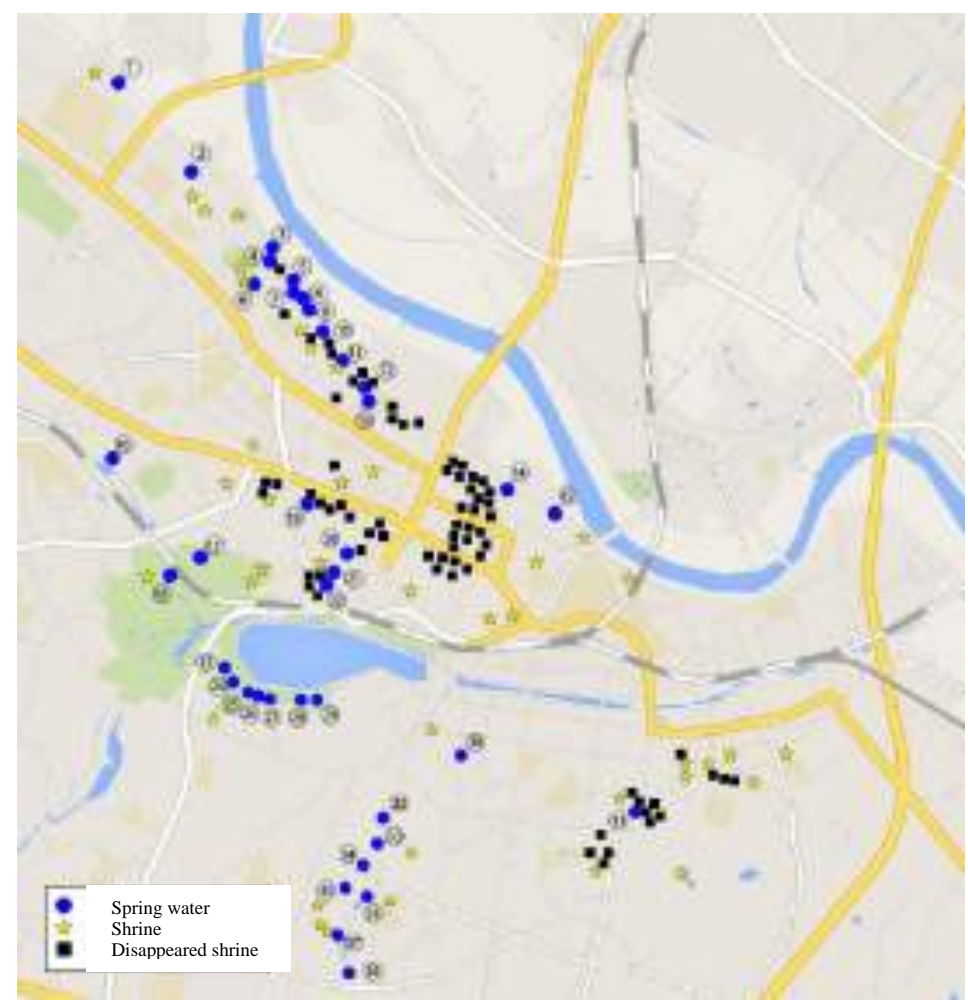

Figure 1: Spring water locations in a central area of Mito 
Takayuki Kumazawa

Human Behaviour in Open Space Around Spring Water in a Central Area of Mito-City in Japan

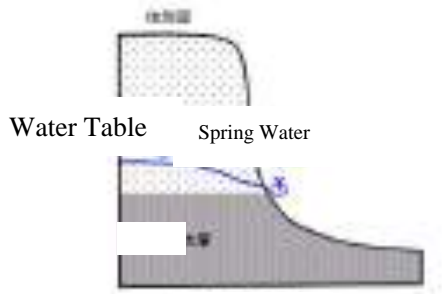

Cliff

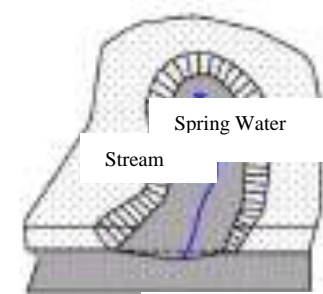

ns Valley

Spring Water

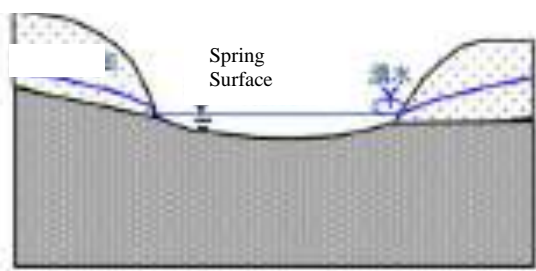

a) Wetland

Figure 2: Types of topography 
Table 1: Condition, topography, and circumstance of springs in a central area of The 1: Condition, topography, and

\begin{tabular}{|c|c|c|c|c|c|c|}
\hline No. & Area & Name & Present Condition & Type of Topography & Installation & $\begin{array}{c}\text { Neighboring Shrine anc } \\
\text { Temple }\end{array}$ \\
\hline 1 & \multirow{15}{*}{ 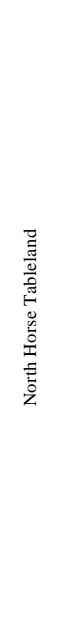 } & Surround Ibaraki University & Small Park & b) & - & present \\
\hline 2 & & Bakui & Park & b) & present & - \\
\hline 3 & & Yougyojyo & Pond & b) & present & - \\
\hline 4 & & Musho & Park & b) & present & - \\
\hline 5 & & Ibaraki high school & Unusable & a) & - & - \\
\hline 6 & & Meisei & Large Park & b) & present & present \\
\hline 7 & & Kyudou & Small Park & a) & - & - \\
\hline 8 & & Nanamagari & Small Park & a) & present & - \\
\hline 9 & & Ochanomizu & Small Park & a) & present & - \\
\hline 10 & & Gion & Small Park & a) & - & - \\
\hline 11 & & Sinnyou & Small Park & a) & present & present \\
\hline 12 & & Taro & Small Park & a) & - & - \\
\hline 13 & & Sensinsen & Small Park & a) & - & - \\
\hline 14 & & Ozawa & Park & a) & present & - \\
\hline 15 & & Kensatu & Unusable & a) & - & - \\
\hline 16 & \multirow{7}{*}{ 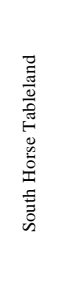 } & Sawawatari & Unusable & a) & - & - \\
\hline 17 & & Togyokusen & Park & a) & present & present \\
\hline 18 & & Gyokuryusen & Park & a) & present & present \\
\hline 19 & & Kodaira & Pond & b) & present & - \\
\hline 20 & & West Valley1 & Unusable & b) & - & present \\
\hline 21 & & West Valley2 & Unusable & b) & - & present \\
\hline 22 & & West Valley3 & Unusable & b) & - & present \\
\hline 23 & \multirow{7}{*}{ 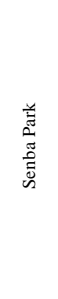 } & Senba Park1 & Park & a) & - & - \\
\hline 24 & & Senba Park2 & Park & a) & - & - \\
\hline 25 & & Senba Park3 & Park & a) & - & - \\
\hline 26 & & Senba Park4 & Park & a) & - & - \\
\hline 27 & & Senba Park5 & Park & a) & - & - \\
\hline 28 & & Senba Park6 & Park & a) & - & - \\
\hline 29 & & Senba Park7 & Park & a) & - & - \\
\hline 30 & \multirow{2}{*}{ 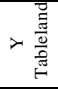 } & Mito kouei & Unusable & a) & - & - \\
\hline 31 & & Yoshida Shrine & Pond & a) & present & present \\
\hline 32 & \multirow{7}{*}{ 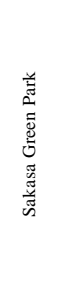 } & Komon Bridge 1 & Park & a) & - & - \\
\hline 33 & & Komon Bridge2 & Park & a) & - & - \\
\hline 34 & & Komon Bridge3 & Park & a) & - & - \\
\hline 35 & & Komon Bridge4 & Park & a) & - & - \\
\hline 36 & & Kashahara & Large Park & a) & present & present \\
\hline 37 & & Sakasa river & Unusable & a) & - & - \\
\hline 38 & & Shiohashi & Large Park & a) & present & - \\
\hline
\end{tabular}


Takayuki Kumazawa

Human Behaviour in Open Space Around Spring Water in a Central Area of Mito-City in Japan

\section{RESULTS ABOUT TRANSFORMATION PROCESS}

Results of all hearings, human action seen in spring space is as follows.

1. Life use is to utilize such as drinking water, washing vegetables and washing cloth.

2. Agricultural use is to utilize for irrigation of paddy and upland fields.

3. Subsistence use is to utilize for breeding fish and producing sake.

4. Hydrophilic use is to utilize for recreation, beautiful landscape and tourist destination.

5. Faith use is to utilize for mental cool down in temples and shrines and guardian god.

6. Educational use is to utilize for biotope and environmental education.

7. Disaster prevention use is to utilize for drinking water and fire-fighting water in a disaster and disaster prevention training.

The reasons why that is no longer used the spring water, were considered as reduction of spring water, changes in the vein, and the water quality deterioration.

Firstly, a transformation of exploitation in the spring water with installation have been described. As a result, the reduction of the amount of water due to urbanization, deterioration of water quality, the water spread, life use and agricultural use of the Edo era was decline. However, in recent years, as installation built by local authority and local community, many people spend a time as a hydrophilic use.

Then, a transformation of human behavior in spring water neighbor shrine and temple have been described. In this section, temples precincts and neighboring spring space were investigated. In spring water neighbor temples and shrines with installation, it had been used together with the temples and shrines. By ritual of celebration and worship is carried out over regular long period of time, the space would have become a base for the local community. And then, these facts had led to the implementation of a variety of spring water use.

Finally, the use of transformation and water spring with installation have been described. 
Table 2: Human behavior in open space based on Installations around spring

\begin{tabular}{|c|c|c|c|c|c|c|c|c|c|}
\hline \multicolumn{10}{|c|}{ water } \\
\hline & Installation & $\begin{array}{l}\text { Neighbor Shrine } \\
\text { and Temple }\end{array}$ & Life use & Agricultural use & Hydrophilic use & Subsistence use & Faith use & $\begin{array}{l}\text { Environmental } \\
\text { Educational use }\end{array}$ & $\begin{array}{c}\text { Disaster } \\
\text { prevention use }\end{array}$ \\
\hline 2 & Existence & - & Decline & Decline & Existence & - & - & - & - \\
\hline 4 & Existence & - & Decline & Decline & Existence & - & - & - & - \\
\hline 8 & Existence & - & Decline & Decline & Existence & - & - & - & - \\
\hline 9 & Existence & - & Decline & Decline & Existence & - & - & - & - \\
\hline 14 & Existence & - & Decline & Decline & Existence & - & - & - & - \\
\hline 38 & Existence & - & Decline & Decline & Existence & - & - & - & - \\
\hline 3 & Existence & - & - & - & - & Decline & - & - & - \\
\hline 19 & Existence & - & - & - & - & Decline & - & - & - \\
\hline 6 & Existence & Existence & - & - & Existence & - & Existence & - & - \\
\hline 11 & Existence & Existence & Decline & Decline & Existence & - & Existence & - & - \\
\hline 17 & Existence & Existence & Decline & - & Existence & - & Existence & Existence & - \\
\hline 18 & Existence & Existence & Decline & - & Existence & - & Existence & & - \\
\hline 31 & Existence & Existence & Decline & - & Existence & - & Existence & - & - \\
\hline 36 & Existence & Existence & Existence & - & Existence & - & Existence & Existence & Existence \\
\hline 1 & - & Existence & Decline & Decline & - & - & - & - & - \\
\hline $20-22$ & - & Existence & Decline & - & Existence & - & - & - & - \\
\hline
\end{tabular}

In Table 2, human behavior in open space based on installations around spring water were shown. Life use and agricultural use has declined in many spring space, hydrophilic use was central amplified by applying installation. In some cases, local authority carried out installations in developing a park, local community build the installations by themselves. In that case, the spring water space has been recognized as a common property of the community. Installation is made at various levels, such as the development of local communities, park development of the city, the development of temples precincts. Spring space located in temples precincts neighborhood installation is has been multilateral use such as faith use, environmental educational use and disaster prevention use. In the central city, as spring water space without installation is not a beautiful natural landscape by the pollution of the water quality, management of the environment was needed such as cleaning the unwanted dust and unsanitary part.

\section{CONCLUSION}

Where residents have positioned as share of the property spring water, installation of the field has been constructed. In specially, centralization place of local community has been formed by the involvement of the spring water space in 
Takayuki Kumazawa

Human Behaviour in Open Space Around Spring Water in a Central Area of Mito-City in Japan

everyday life. There is a difference in the transformation and nestled of exploitation by the function and history of spring water. Where spring water space is integrally utilized as a function of the temples, a special installation is performed. There, through the ritual of regular festivals and worship, it became a base for local communities. Spring water have been a wide variety available, such as life use, agricultural use, hydrophilic use, faith use, disaster prevention use and educational use, etc..

From the above findings, the local community and the local authority should develop the spring water space with installation and should make an involvement each other. At the same time, in order to encourage a diversified spring water use, and should be cross-promoted how to use that diversity. Specifically, to achieve the network by walking or events spring water. While achieving a hydrophilic use that can be round as a promenade, inheritance of faith and local culture, and should promote the complex use so that it can at the same time experience and environmental learning. In addition, the implementation of the initiatives utilizing the spring water in the disaster drill away. To learn the processing method necessary to use the spring as water for life. It is important to assemble a diversified use.

\section{ACKNOWLEDGMENT}

The authors would like to thank Residens and city officer in Mito-city of Japan. We are also like to thank referees for the fruitful comments.

\section{REFERENCES}

Burton Litton Jr. (1974). Water and Landscape: An Aesthetic Overview of the Role of Water in the Landscape. New York: Water information Centre Inc. Charles Moore (1957). Water and Architecture. Princeton University. 